\title{
Warthog Framework Update: Depletion Capabilities
}

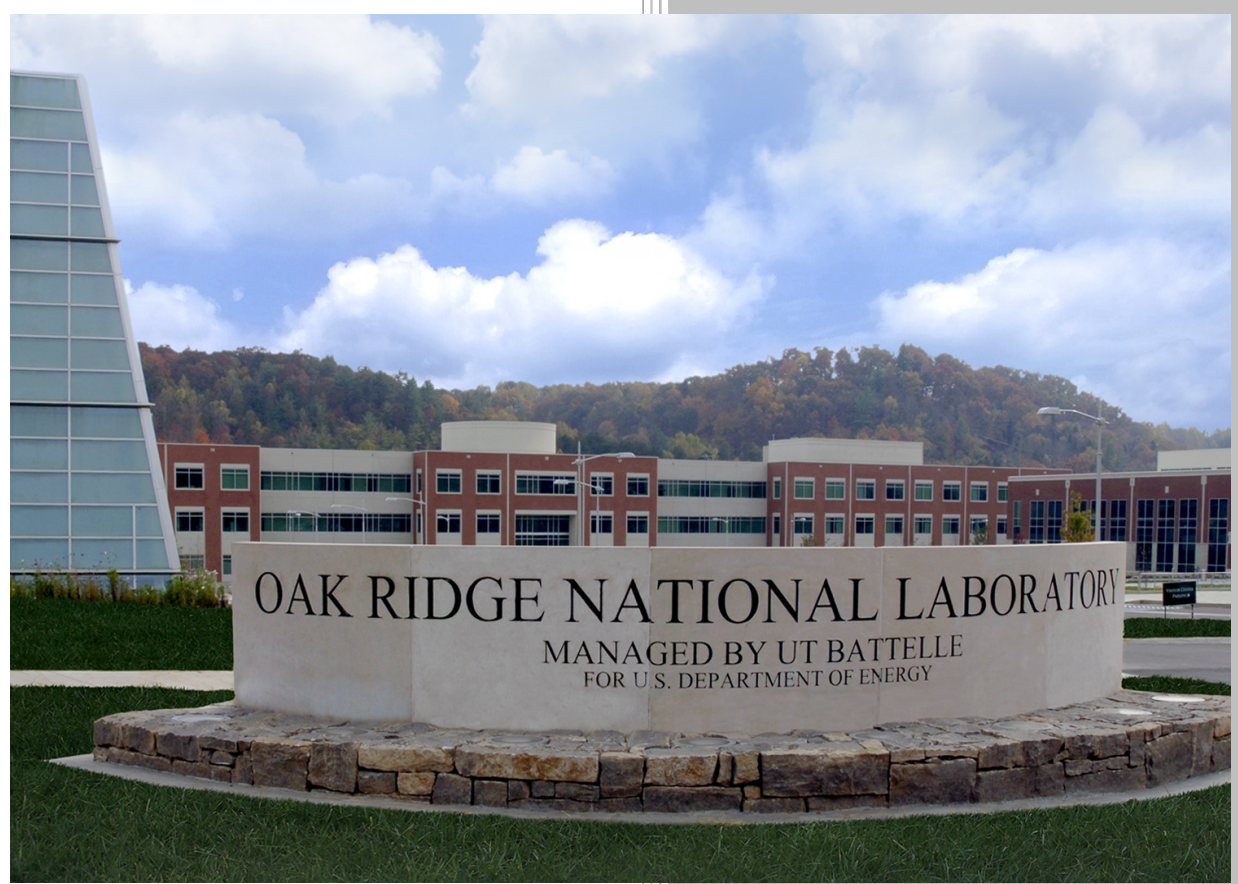

Approved for public release. Distribution is unlimited.

Kevin J. Dugan

Shane W. D. Hart

Bradley T. Rearden

March 31, 2018 


\section{DOCUMENT AVAILABILITY}

Reports produced after January 1, 1996, are generally available free via US Department of Energy (DOE) SciTech Connect.

Website: www.osti.gov/

Reports produced before January 1, 1996, may be purchased by members of the public from the following source:

National Technical Information Service

5285 Port Royal Road

Springfield, VA 22161

Telephone: 703-605-6000 (1-800-553-6847)

TDD: $703-487-4639$

Fax: 703-605-6900

E-mail: info@ntis.gov

Website: http://classic.ntis.gov/

Reports are available to DOE employees, DOE contractors, Energy Technology Data Exchange representatives, and International Nuclear Information System representatives from the following source:

Office of Scientific and Technical Information

PO Box 62

Oak Ridge, TN 37831

Telephone: 865-576-8401

Fax: 865-576-5728

E-mail: report@osti.gov

Website: http://www.osti.gov/contact.html

This report was prepared as an account of work sponsored by an agency of the United States Government. Neither the United States Government nor any agency thereof, nor any of their employees, makes any warranty, express or implied, or assumes any legal liability or responsibility for the accuracy, completeness, or usefulness of any information, apparatus, product, or process disclosed, or represents that its use would not infringe privately owned rights. Reference herein to any specific commercial product, process, or service by trade name, trademark, manufacturer, or otherwise, does not necessarily constitute or imply its endorsement, recommendation, or favoring by the United States Government or any agency thereof. The views and opinions of authors expressed herein do not necessarily state or reflect those of the United States Government or any agency thereof. 
Reactor and Nuclear Systems Division

\title{
Warthog Framework Update: Depletion Capabilities
}

\author{
Kevin J. Dugan \\ Shane W. D. Hart \\ Bradley T. Rearden
}

Date Published: March 31, 2018

\author{
Prepared by \\ OAK RIDGE NATIONAL LABORATORY \\ Oak Ridge, TN 37831-6283 \\ managed by \\ UT-Battelle, LLC \\ for the \\ US DEPARTMENT OF ENERGY \\ under contract DE-AC05-00OR22725
}





\section{CONTENTS}

LIST OF FIGURES $\ldots \ldots \ldots \ldots \ldots \ldots \ldots \ldots \ldots \ldots \ldots \ldots \ldots$

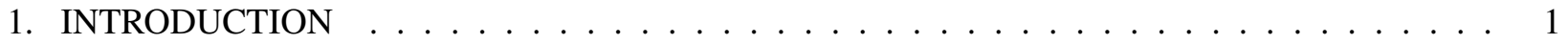

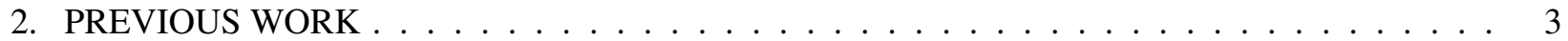

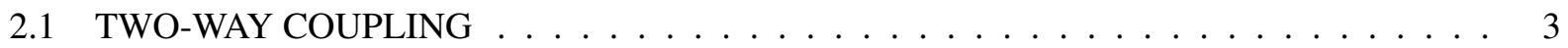

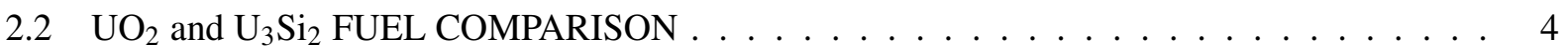

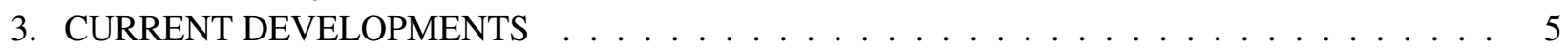

3.1 REDUCTION OF TECHNICAL DEBT $\ldots \ldots \ldots \ldots \ldots \ldots \ldots \ldots \ldots$

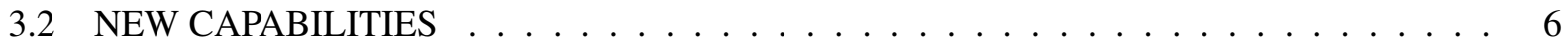

3.2 .1 Uniform depletion in fuel . . . . . . . . . . . . . . . . 7

3.2 .2 Radial depletion profile in fuel $\ldots \ldots \ldots \ldots \ldots$

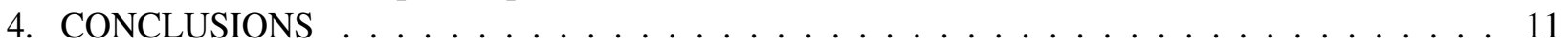

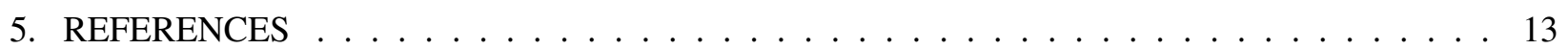





\section{LIST OF FIGURES}

1 Iteration scheme for Warthog. . . . . . . . . . . . . . . . . 3

2 Power and temperature comparison between $\mathrm{ATF}$ and $\mathrm{UO}_{2}$ fuel pins. . . . . . . . . . . . 4

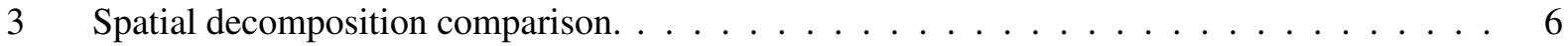

4 Iteration scheme for Warthog with ORIGEN depletion. . . . . . . . . . . . . . . . 7

5 Evolution of selected fuel isotopes over 3.5 days. . . . . . . . . . . . . . 8

6 Material zones for radial depletion geometry. Red is moderator, orange is cladding, and inner rings are fuel depletion zones. . . . . . . . . . . . . . . . . . 8

7 Radial distribution of ${ }^{135} \mathrm{Xe},{ }^{149} \mathrm{Sm}$, and ${ }^{239} \mathrm{Pu}$ during depletion. Ordinate axis denotes

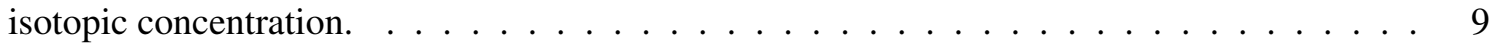

8 Radial distribution of Power during depletion $\ldots \ldots \ldots \ldots$ 



\section{INTRODUCTION}

The Nuclear Energy Advanced Modeling and Simulation (NEAMS) program the US Department of Energy (DOE) Office of Nuclear Energy supports two simulation frameworks to provide advanced simulation techniques for analyzing nuclear reactors. Primarily at Idaho National Laboratory (INL), the fuels product line (FPL) is developing the fuel performance code BISON from Hales et al. [2016], which depends on the Multiphysics Object-Oriented Simulation Environment (MOOSE) framework developed by Gaston et al. [2009]. Likewise, at Argonne National Laboratory (ANL), in the reactor product line (RPL), PROTEUS is being developed by Lee et al. [2013] and Nek5000 by Fischer et al. [2015] based on the Simulation-based High-efficiency Advanced Reactor Prototyping (SHARP) framework from Tautges et al. [2013]. MOOSE employs a bottom-up approach to multiphysics coupling, where component codes are built upon a common framework. SHARP employs a top-down approach in which legacy component codes are connected after being separately developed. Each approach has benefits and disadvantages, but this work focuses on having the two approaches work in harmony.

The Warthog project, developed under the integration product line (IPL) at Oak Ridge National Laboratory (ORNL), has been shown to successfully couple codes from BISON and PROTEUS frameworks in a two-way fashion, as demonstrated by Hart and Rearden [2017]. This coupling procedure includes a march to steady state, with BISON providing fuel temperatures and PROTEUS providing the power. XSProc from SCALE (Rearden and Jessee [2016]) served as an intermediary to evaluate the temperature-dependent material cross sections. Results were presented that highlighted the significant differences in pin power profiles for $\mathrm{UO}_{2}$ and $\mathrm{U}_{3} \mathrm{Si}_{2}$. While significant improvements were made to Warthog's modeling capabilities, significant technical debt existed due to the rapid development process. The work described herein focuses on how this technical debt was reduced and provides a more stable design for the Warthog framework.

This report highlights how technical debt was reduced in three major areas of the Warthog framework. The first method was to update Warthog to a MOOSE native application under the MOOSE build system. This change provides many benefits, including framework testing support. The second method was to remove the Mesh-Oriented Database (MOAB) developed by Tautges et al. [2004] as an intermediary for solution transfer between SHARP and BISON. This change improves the parallel performance by allowing for a more aggressive spatial decomposition when necessary. The third method was to extend the PROTEUS code base to use a later version of the Portable, Extensible Toolkit for Scientific Computation (PETSc) developed by Balay et al. [2017], which the MOOSE framework also supports.

This report also describes two new capabilities in Warthog: the integration of a Method of Characteristics (MoC) transport solver based on the PROTEUS code of Jung et al. [2017] and the integration of the ORIGEN depletion solver (Rearden and Jessee [2016]). The MoC solver allows PROTEUS to handle cases in which low density regions are present; the second order $S_{N}$ solver previously used had difficulty converging when low density regions were present. The ORIGEN depletion module was introduced to Warthog to update isotopic concentrations in PROTEUS due to depletion. In the previous version of Warthog, all cross sections were evaluated using fresh fuel isotopic concentrations. The current implementation of Warthog has the ability to perform two-way coupling between BISON and PROTEUS, with the possibility of updating the nuclide concentrations used for cross section evaluation due to depletion. 



\section{PREVIOUS WORK}

The work performed on Warthog in the 2017 fiscal year (FY) focused on introducing two-way coupling between the PROTEUS and BISON modules. This progress allowed Warthog to update the temperature-dependent cross sections needed in PROTEUS. Also, a comparison between the power profiles within $\mathrm{UO}_{2}$ fuel and $\mathrm{U}_{3} \mathrm{Si}_{2}$ fuel was explored to show the need for determining the detailed power distribution within a fuel pin.

\subsection{TWO-WAY COUPLING}

Warthog couples together PROTEUS and BISON by giving PROTEUS cross sections evaluated at the current temperature. The temperature is evaluated by BISON, which is given the power calculated in PROTEUS. SCALE's XSProc module was chosen to evaluate the cross sections for a given temperature distribution, but other cross section processors could be integrated such as $\mathrm{MC}^{2}-3$ Lee and Yang [2017]. This coupling scheme is shown in Figure 1.

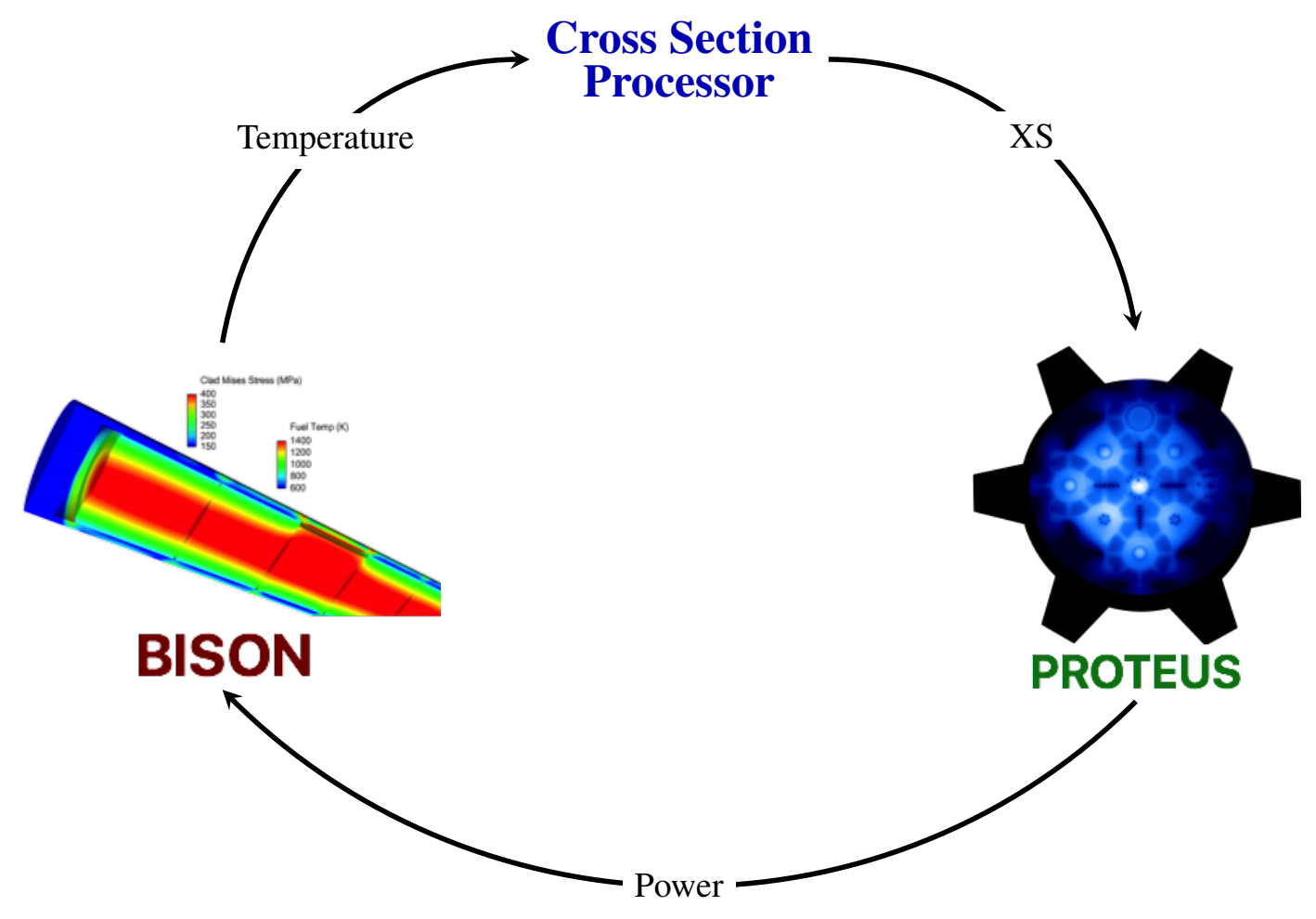

Figure 1. Iteration scheme for Warthog.

The coupling strategy in Figure 1 is used to produce steady state power and temperature distributions. While PROTEUS has the capability to solve a quasi-static evolution problem, only the eigenvalue solver is used to produce the power distribution inside a march to steady-state iteration scheme. 


\section{$2.2 \mathrm{UO}_{2}$ and $\mathrm{U}_{3} \mathrm{Si}_{2}$ FUEL COMPARISON}

When evaluating the temperature profile, stand-alone BISON uses the same radial power profile regardless of the fuel type. Warthog was used to show that different fuel types can produce different power profiles, and thus different temperature distributions. A standard $\mathrm{UO}_{2}$ fuel was compared to $\mathrm{U}_{3} \mathrm{Si}_{2}$ fuel to show the difference in power profiles and the effect this has on the temperature profile. Figure 2 shows the power and temperature profiles from these two cases both with a power of $1 \mathrm{~kW}$; the $\mathrm{U}_{3} \mathrm{Si}_{2}$ fuel is labeled ATF for accident-tolerant fuel. For both cases the fuel radius is $0.43815 \mathrm{~cm}$, with a cladding thickness of $0.0749 \mathrm{~cm}$, and a fuel pitch of $1.2954 \mathrm{~cm}$.

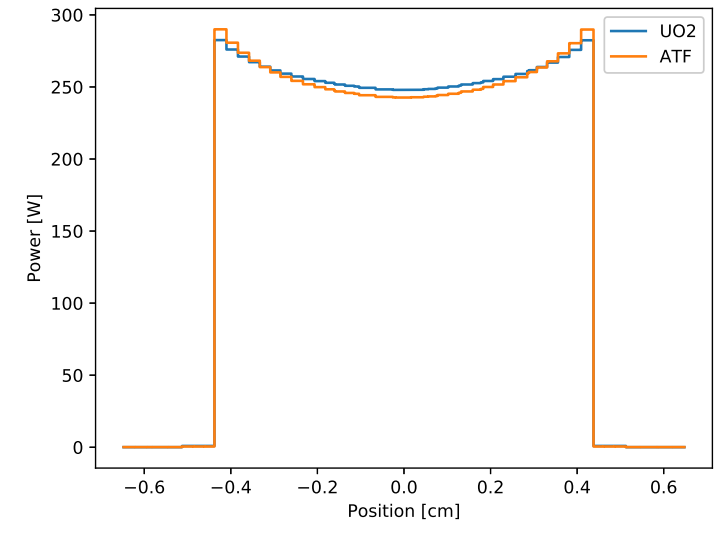

(a) Power profile

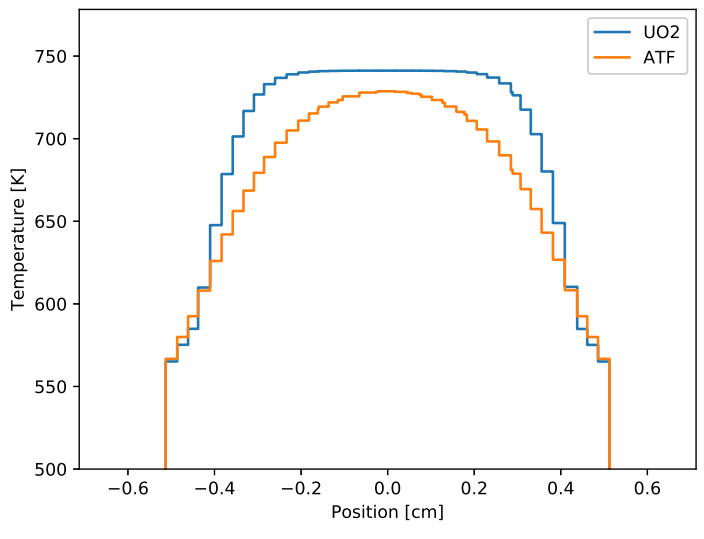

(b) Temperature profile

Figure 2. Power and temperature comparison between $\mathrm{ATF}$ and $\mathrm{UO}_{2}$ fuel pins.

Figure 2a shows that the power profile for $\mathrm{U}_{3} \mathrm{Si}_{2}$ is more peaked than the $\mathrm{UO}_{2}$ fuel. The ratio of the edge power to center power for the $\mathrm{UO}_{2}$ fuel is 1.140, while the same ratio for the $\mathrm{U}_{3} \mathrm{Si}_{2}$ fuel is higher at 1.195. The effect on temperature distribution is shown in Figure $2 \mathrm{~b}$, where the $\mathrm{UO}_{2}$ fuel has a higher centerline temperature than the $\mathrm{U}_{3} \mathrm{Si}_{2}$ fuel. 


\section{CURRENT DEVELOPMENTS}

The current work on Warthog has been focused on two objectives: (1) reducing the technical debt, thus making Warthog a more stable software package and (2) incorporating new solution capabilities into Warthog. The first objective allows the developers to produce a more effective product and have confidence that older features are working correctly when new features are added. Due to the rapid development cycle of the MOOSE package, Warthog had previously frozen a version of MOOSE and no longer received updates. This could lead to incompatibility between the two codes, and it also eliminates the ability to receive fixes to any problems discovered. If an update in MOOSE were needed by Warthog, it would have been difficult to adapt Warthog to be able to accept the fix. The second objective was the introduction of two new capabilities in Warthog: the use of a MoC transport solver and the ability to handle the evolution of nuclide concentrations under irradiation.

\subsection{REDUCTION OF TECHNICAL DEBT}

Technical debt is a term used within software development which carries the same connotation as financial debt (Cunningham). Debt can accumulate during an early release of a software package if developers write code that is quick to produce in the short term yet is time consuming to maintain in the long term.

Technical debt can be reduced by refactoring the original code to be more maintainable. Reducing the technical debt in Warthog was addressed by (1) making Warthog a MOOSE-native app, (2) replacing solution transfers through MOAB with Data Transfer Kit (DTK), and (3) modifying PROTEUS to use the same version of PETSc as that supported by MOOSE.

The previous implementation of Warthog had a significant amount of technical debt. The top priority for reducing technical debt was to have a testing framework so that developers could have confidence that their changes were not introducing unintended behaviors in Warthog. Since MOOSE has an extensive testing framework and is being rapidly developed, it was decided to make Warthog a MOOSE-native app. This allows Warthog to leverage MOOSE's build system and testing framework as opposed to the former method in which Warthog linked to MOOSE, which consisted of copying the MOOSE-generated libraries into a common install directory.

While Warthog was being ported to MOOSE's build system, a continuous integration (CI) system was being established to test any changes made to the Warthog source repository. This system provides immediate feedback to developers if they introduce any unintended side effects. This CI system is also used to ensure that any changes to the MOOSE framework do not break Warthog. As was mentioned earlier, the MOOSE framework is actively developed, so ensuring that Warthog and MOOSE remain compatible requires continuous monitoring. A nightly check is run to determine if the day's development on MOOSE is still compatible with Warthog. Periodically, Warthog's version of MOOSE is updated to the most recent version if there are no conflicts.

A significant portion of Warthog's capabilities is realized through the transfer of solutions between PROTEUS and BISON. BISON uses libMesh structures to store its mesh and solutions, while PROTEUS uses custom structures to store its mesh and solutions. However, PROTEUS can interface with MOAB through the SHARP framework. Since DTK can interface with both libMesh and MOAB, the original Warthog version used PROTEUS's ability to interface with MOAB to facilitate the transfer of solutions. It was discovered that PROTEUS's interface to MOAB limited the number of spatial decompositions to two, as shown in Figure 3a. 


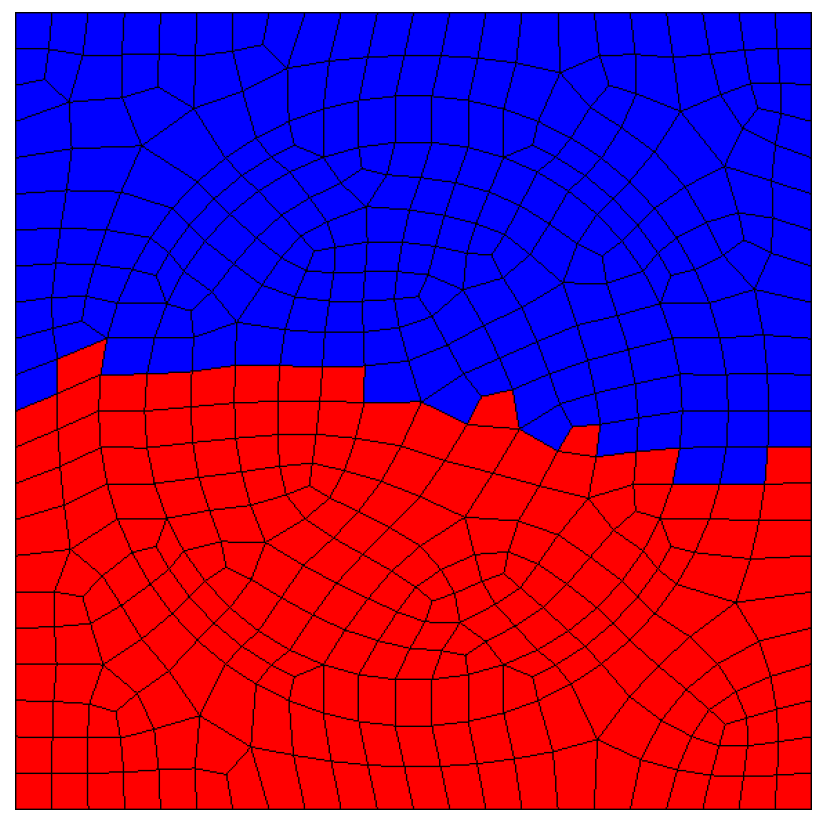

(a) Spatial decomposition using MOAB limited to 2 processors

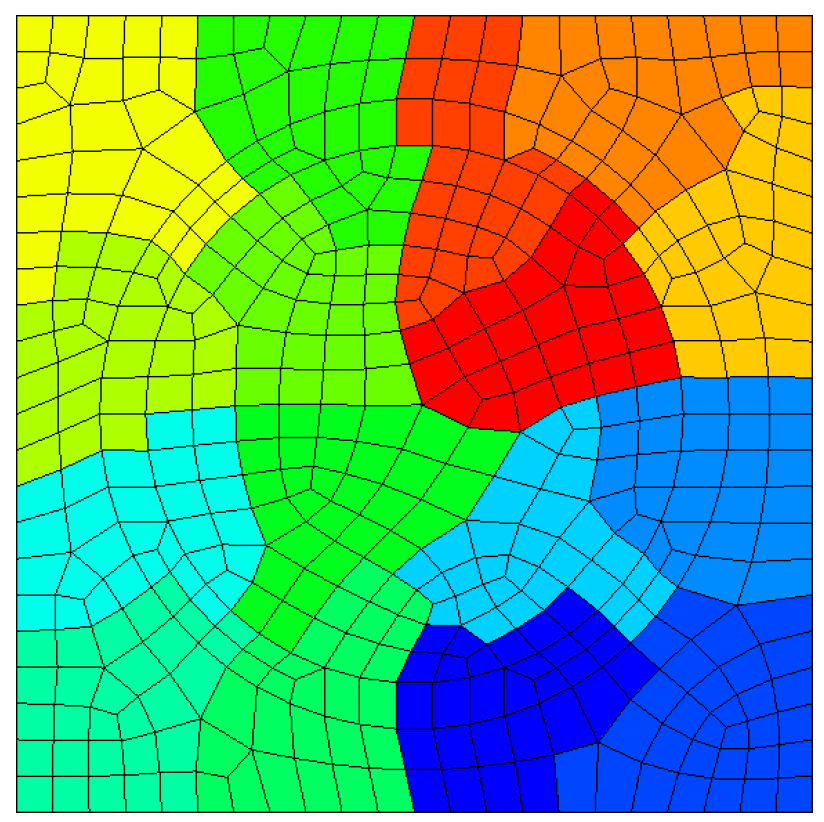

(b) Spatial decomposition with DTK on 16 processors

Figure 3. Spatial decomposition comparison.

Being limited to only two spatial decompositions severely hindered the parallel performance of Warthog, so it was decided to forego the intermediate step passing through MOAB. DTK offers a point-cloud interface in which a set of spatial points and solution values associated with those points can be transferred between spatial meshes. This interface was chosen to provide solution transfers between PROTEUS and BISON, with the element centroids being the support points for solutions. With this new solution transfer implementation, the spatial decomposition is no longer limited to two, as shown in Figure $3 \mathrm{~b}$.

A final area way that technical debt was reduced was through upgrading the version of PETSc used by PROTEUS. The latest version of PETSc that PROTEUS could support was version 3.4.5, while the earliest version MOOSE supported was version 3.6.4. This discrepancy in PETSc versions created difficulties in keeping Warthog compatible with both PROTEUS and MOOSE. An extension was made to PROTEUS to incorporate the newer version of PETSc and has relieved the difficulties in working with the older version of PETSc. This update to PROTEUS has been communicated with the developers and is awaiting inclusion in the PROTEUS repository.

\subsection{NEW CAPABILITIES}

Two significant capabilities were added to the Warthog framework in the first half of FY 2018. One was the integration of a MoC transport solver related to PROTEUS called MOCEX. This solver uses the same two dimensional spatial meshes as the former PROTEUS-SN solver, but it extrudes the 2D mesh into three dimensions. The second order formulation of PROTEUS-SN causes it to converge slowly when low density regions are present in the domain, such as the helium gas gap in conventional light water reactor (LWR) fuel. MOCEX does not incur such difficulties when low density regions are present. 
The second capability added was the integration of the ORIGEN depletion solver. ORIGEN solves the Bateman evolution equations for isotopic concentrations over a time interval given a one energy group scalar flux. ORIGEN provides updated isotopic concentrations to the XSProc cross section processor when given the flux calculated in PROTEUS; this coupling strategy is shown in Figure 4.

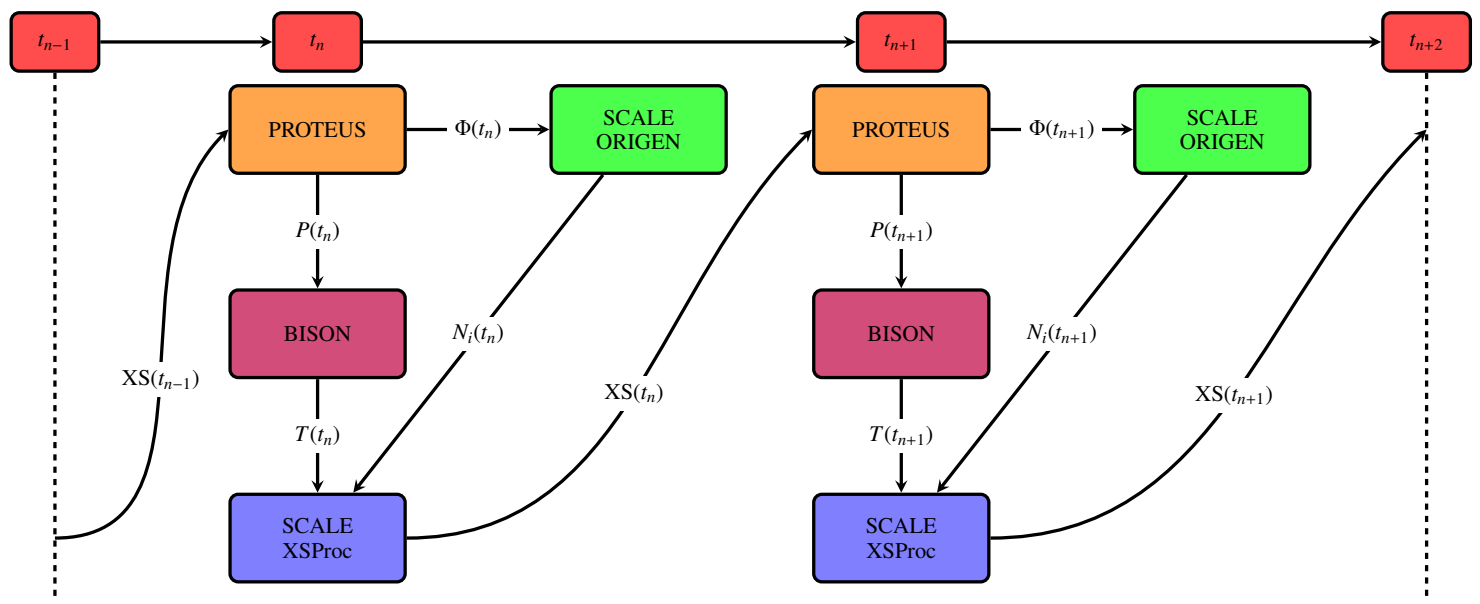

Figure 4. Iteration scheme for Warthog with ORIGEN depletion.

At each timestep, PROTEUS calculates a scalar flux and a power distribution. The scalar flux is sent to ORIGEN to produce updated isotopic concentrations, while the power distribution is transferred to BISON. The temperature profile is calculated by BISON in the same way as discussed in Section 2. XSProc uses the updated temperature from BISON and the updated isotopic concentrations from ORIGEN to produce a new set of cross sections for PROTEUS in the next timestep. This scheme is known as operator splitting and can provide a suitable solution to coupled physics simulations, as discussed in Ragusa and Mahadevan [2009].

\subsubsection{Uniform depletion in fuel}

The new depletion capabilities in Warthog were tested on a fresh LWR fuel pin. The fuel radius for the fuel pin is $0.4382 \mathrm{~cm}$, with a clad thickness of $0.0749 \mathrm{~cm}$, and a pitch of $1.2954 \mathrm{~cm}$; all sides have reflecting boundary conditions. The pin is irradiated for 3.5 days at $40 \mathrm{~kW}$ so that the build up of selected isotopes can be observed. Figure 5a shows the build up of the short-lived poisons ${ }^{135} \mathrm{Xe}$ and ${ }^{149} \mathrm{Sm}$; the equilibrium concentrations are reached after $\sim 15$ hrs.

The build up of ${ }^{236} \mathrm{U}$, which is initially not present in the fuel, occurs quickly and approaches a saturation concentration at the end of the simulation. The other isotopes of uranium shown in Figure 5b are depleted only slightly over the simulation: that is, the ${ }^{238} \mathrm{U}$ concentration is depleted by only $1.4 \%$. The plutonium isotopic build up is shown in Figure 5c, where the fresh fuel contains no plutonium, and the isotopic concentrations increase steadily over the 3.5-day simulation. 


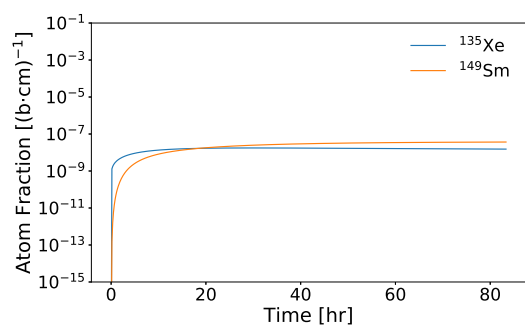

(a) Xenon and samarium isotopes

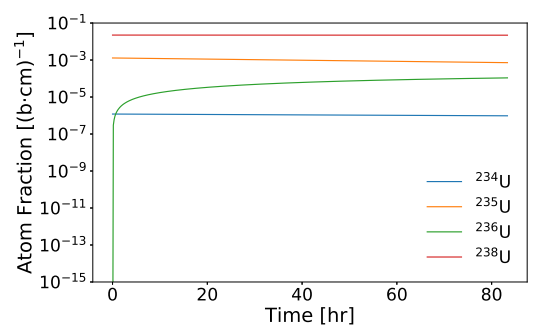

(b) Uranium isotopes

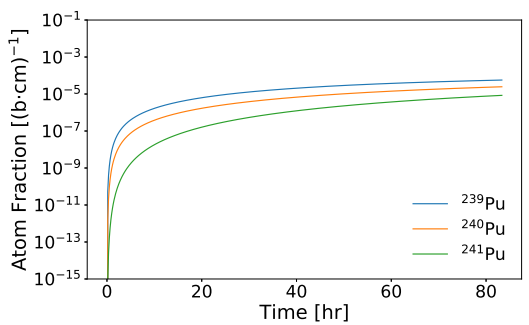

(c) Plutonium isotopes

Figure 5. Evolution of selected fuel isotopes over 3.5 days.

\subsubsection{Radial depletion profile in fuel}

While many users will only use a single depletion zone per fuel pin, Warthog has the ability to specify multiple depletion zones within the fuel. The multiple depletion zones can provide insight into the radial profile of the concentration of nuclides.

The depletion zones capability in Warthog was tested using the same fuel pin as in Section 3.2.1, but with the addition of five depletion zones within the fuel pin. This geometry is shown in Figure 6, where the five inner rings are of the same fresh $\mathrm{UO}_{2}$ fuel material, the outer orange ring is of zircaloy clad material, and the outer red region is water moderator. The fuel pin was simulated over 3.5 days with a time step of $10 \mathrm{~min}$.

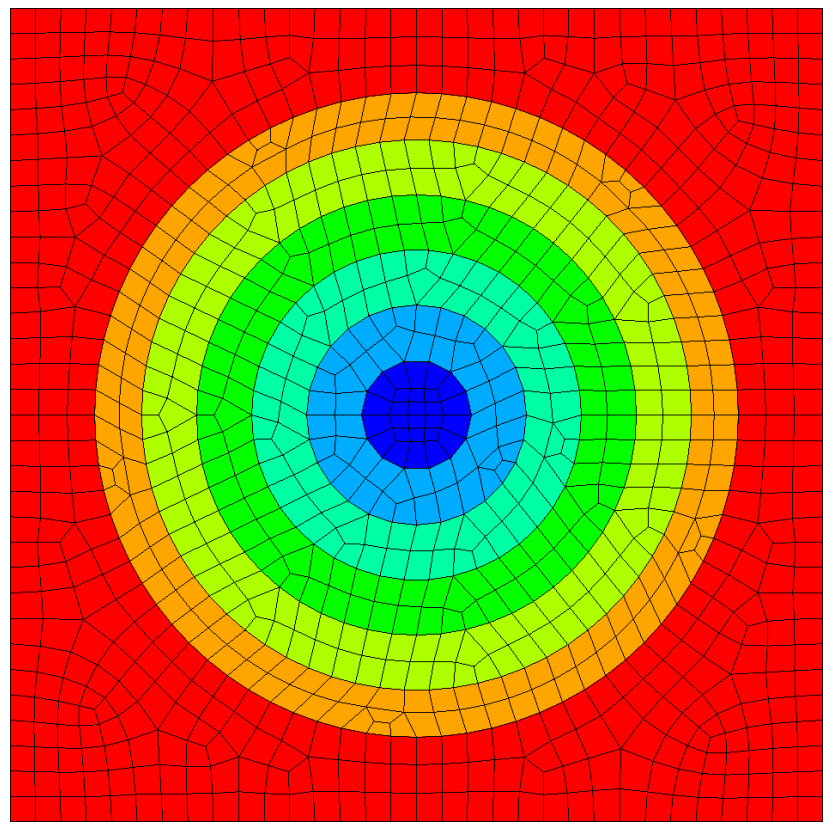

Figure 6. Material zones for radial depletion geometry. Red is moderator, orange is cladding, and inner rings are fuel depletion zones.

The radial distribution of ${ }^{135} \mathrm{Xe},{ }^{149} \mathrm{Sm}$, and ${ }^{239} \mathrm{Pu}$ is shown in Figure 7 at three times during the simulation. The three times (10 min, $16 \mathrm{hr}$, and $60 \mathrm{hr}$ ) were chosen to reflect short, medium, and long time scales 
respectively. ${ }^{135} \mathrm{Xe}$ and ${ }^{149} \mathrm{Sm}$ appear in higher concentrations near the outer ring of the fuel during the early stage of the simulation, but are then burned more in the outer rim once equilibrium is reached.

The concentration of ${ }^{239} \mathrm{Pu}$ increases slowly during the simulation, and is linearly in the radial direction. The Rim Effect does not appear in Figure 7i as one would expect; this is due to the way the flux is passed from PROTEUS to ORIGEN. In the current implementation, only the one-group flux magnitude per block is passed to the depletion solver. A more realistic implementation would include passing the multigroup flux per block into ORIGEN so that the proper reaction rates could be calculated. Such an implementation is planned for the second half of FY 2018.

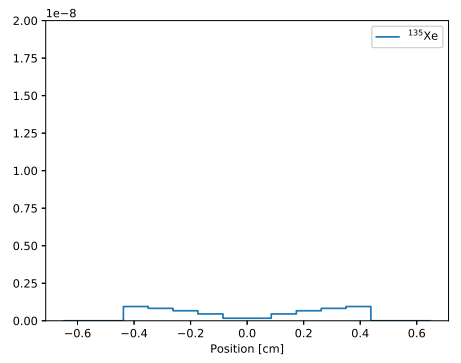

(a) ${ }^{135} \mathrm{Xe}$ at $10 \mathrm{~min}$

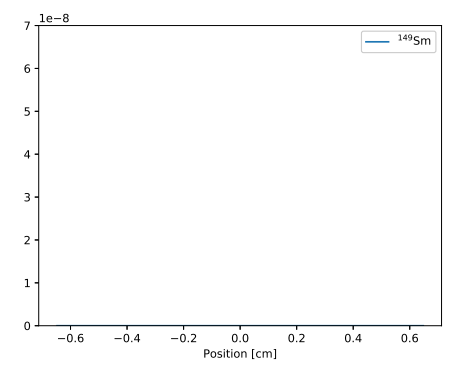

(d) ${ }^{149} \mathrm{Sm}$ at $10 \mathrm{~min}$

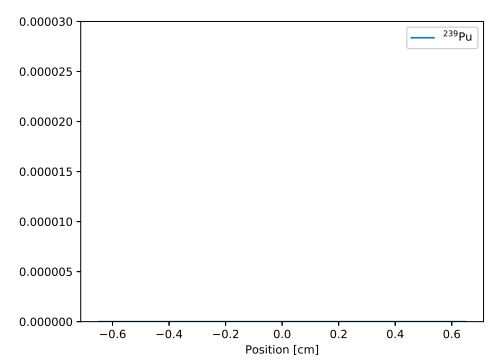

(g) ${ }^{239}$ Pu at $10 \mathrm{~min}$

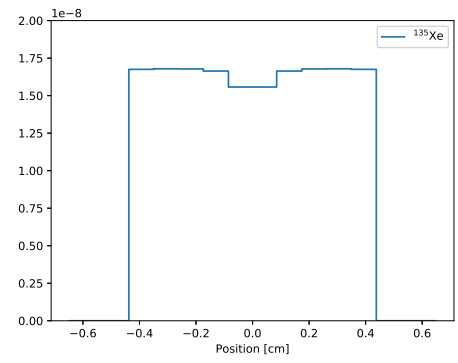

(b) ${ }^{135} \mathrm{Xe}$ at $16 \mathrm{hr}$

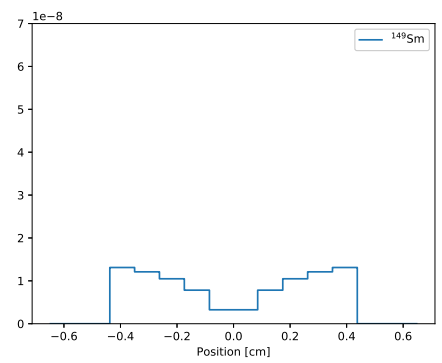

(e) ${ }^{149} \mathrm{Sm}$ at $16 \mathrm{hr}$

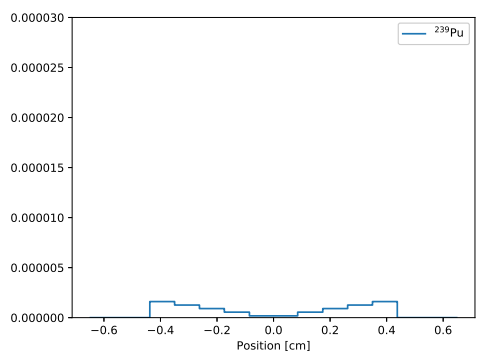

(h) ${ }^{239} \mathrm{Pu}$ at $16 \mathrm{hr}$

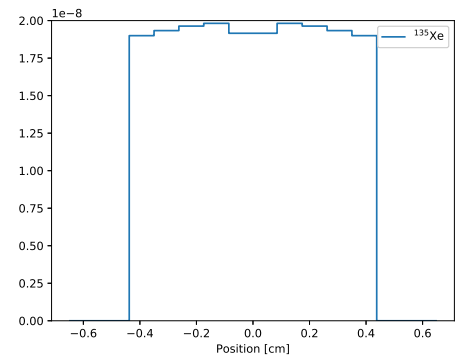

(c) ${ }^{135} \mathrm{Xe}$ at $60 \mathrm{hr}$

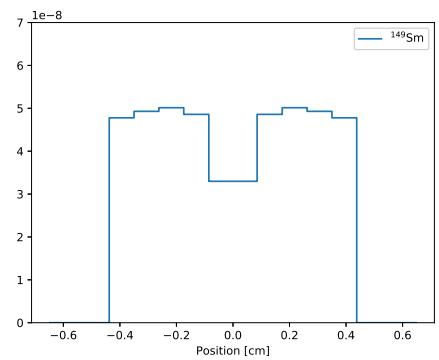

(f) ${ }^{149} \mathrm{Sm}$ at $60 \mathrm{hr}$

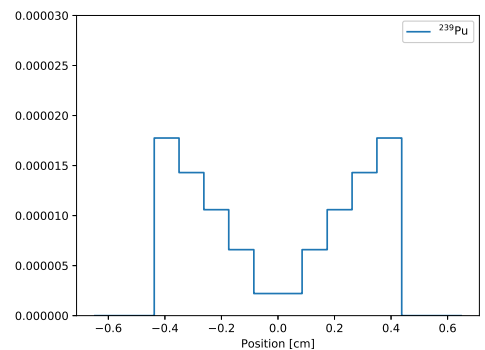

(i) ${ }^{239} \mathrm{Pu}$ at $60 \mathrm{hr}$

Figure 7. Radial distribution of ${ }^{135} \mathrm{Xe},{ }^{149} \mathrm{Sm}$, and ${ }^{239} \mathrm{Pu}$ during depletion. Ordinate axis denotes isotopic concentration.

The radial power distribution during the depletion zone simulation is shown in Figure 8. The power profile 
remains nearly constant during the simulation, which was unexpected for the authors. Given the higher concentration of Xe and Sm poison and the build up of Pu near the edge of the fuel pin, it was expected that the power profile would be perturbed near the fuel pin edge. This could indicate that either the impact of these isotopes being concentrated along the fuel rim has a smaller than expected effect on the power profile, or that the isotopic concentrations are not being properly communicated to the PROTEUS transport solver during the simulation. Further investigation is needed to verify that the isotopic concentrations are being properly updated in PROTEUS.

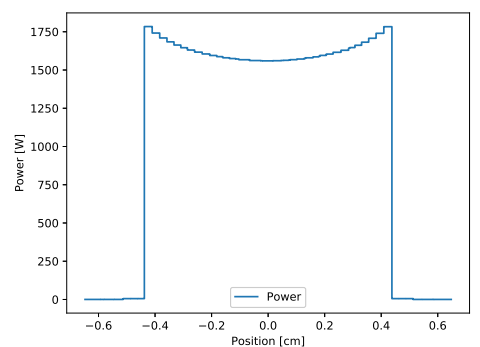

(a) Power at 10 min

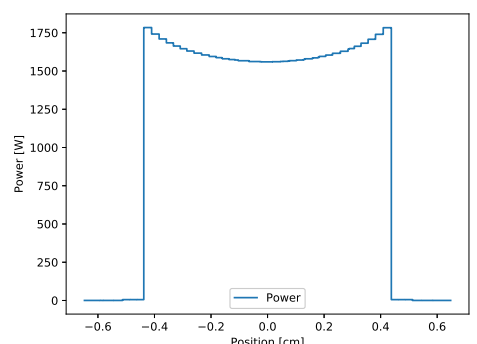

(b) Power at $16 \mathrm{hr}$

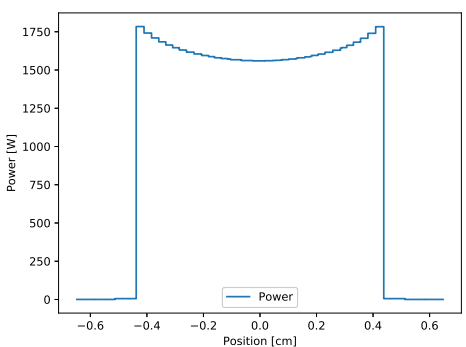

(c) Power at $60 \mathrm{hr}$

Figure 8. Radial distribution of Power during depletion

The depletion of materials has a significant impact on the behavior of fuel materials during irradiation. Warthog provides the capability to track the evolution of isotopes during a time dependent simulation with a radial depletion profile. 


\section{CONCLUSIONS}

The present work in Warthog has focused on making the framework more stable and robust by removing a portion of the technical debt incurred through the rapid development process during FY 2017. With Warthog relying on the MOOSE test suite and build system, developers can reduce regressions due to incompatibilities between Warthog and MOOSE. The removal of Warthog's dependency on MOAB to transfer solutions between PROTEUS and BISON has increased the number of spatial decompositions possible for Warthog.

The introduction of the MOCEX solver from PROTEUS will allow Warthog to solve previously difficult cases where low density material was present, such as the fuel-clad gap of LWRs. The new depletion capabilities introduced in Warthog allow for new analyses of how changing material properties effect the power and temperature distributions within fuel. The ability to perform zone depletion simulations in Warthog provides high resolution insight into the behavior of isotopic evolution during a transient. However, further investigation is needed to verify that the proper isotopic concentrations are being communicated back to PROTEUS.

The progress made on the Warthog framework shows promise for coupling codes from both the FPL and RPL, but more work can be done to extend the capabilities of Warthog. Some areas for future development should include higher order solution transfers between Warthog modules; the current use of DTK's point-cloud model allows for piece-wise, constant solution transfers. Slight modification to the current use of the point-cloud model would produce piece-wise linear solutions, but a better approach would include developing an $\mathrm{L}_{2}$ projection transfer within DTK; an $\mathrm{L}_{2}$ solution projection would minimize the error introduced by the solution transfer.

Additionally, the coupling scheme used to integrate the ORIGEN depletion solver pictured in Figure 4 is at best first-order accurate in time. A higher convergence order could be achieved by introducing an iteration scheme among PROTEUS, BISON, and XSProc to converge the scalar flux, accounting for temperature feedback before sending this flux to ORIGEN.

A future capability for Warthog includes the integration of the Nek5000 computational fluid dynamics (CFD) code developed at ANL. This capability would allow Warthog to send BISON a more accurate clad surface heat flux. Currently, this boundary condition is a constant, imposed temperature. This integration can be facilitated by using the recently developed Giraffe MOOSE app. 



\section{REFERENCES}

\section{References}

S. Balay, S. Abhyankar, M. F. Adams, J. Brown, P. Brune, K. Buschelman, L. Dalcin, V. Eijkhout, W. D. Gropp, D. Kaushik, M. G. Knepley, D. A. May, L. C McInnes, K. Rupp, P. Sanan, B. F. Smith, S. Zampini, H. Zhang, and H. Zhang. PETSc users manual. Technical Report ANL-95/11 - Revision 3.8, Argonne National Laboratory, 2017. URL http://www.mcs.anl.gov/petsc.

W. Cunningham. The WyCash portfolio management system. http://c2.com/doc/oopsla92.html. Accessed: 2018-03-22.

P. Fischer, J. Lottes, S. Kerkemeier, O. Marin, K. Heisey, A. Obabko, E. Merzari, and Y. Peet. Nek5000: User's Manual. Technical Report ANL/MCS-TM-351, Argonne National Laboratory, 2015.

D. Gaston, C. Newman, G. Hansen, and D. Lebrun-Grandié. MOOSE: A parallel computational framework for coupled systems of nonlinear equations. Nuclear Engineering and Design, 239(10): 1768-1778, October 2009.

J. D. Hales, R. L. Williamson, S. R. Novascone, G. Pastore, B. W. Spencer, et al. BISON Theory Manual: The Equations Behind Nuclear Fuel Analysis. Technical Report INL/EXT-13-29930, Idaho National Laboratory, 2016.

S. W. D. Hart and B. T. Rearden. Warthog - Coupling Status Update. Technical Report ONRL/LTR-2017/325, Oak Ridge National Laboratory, June 2017.

Y. S. Jung, C. H. Lee, and M. A. Smith. Verification of High-Fidelity Neutronics Code PROTEUS for C5G7 Benchmark Problems. Transactions of the American Nuclear Society, 116:1042-1044, June 2017.

C. H. Lee, A. Marin-Lafleche, and M. A. Smith. Development of Cross Section Library and Application Programming Interface (API). Technical Report ANL/NE-13/15, Argonne National Laboratory, September 2013.

Changho Lee and Won Sik Yang. MC ${ }^{2}-3$ : Multigroup Cross Section Generation Code for Fast Reactor Analysis. Nuclear Science and Engineering, 187(3):268-290, 2017.

J. C. Ragusa and V. S. Mahadevan. Consistent and accurate schemes for coupled neutronics thermal-hydraulics reactor analysis. Nuclear Engineering and Design, 239:566-579, 2009.

B. T. Rearden and M. A. Jessee. SCALE Code System, Version 6.2.1. Technical Report ORNL/TM-2005/39, Oak Ridge National Laboratory, Oak Ridge, TN, 2016.

T. J. Tautges, R. Meyers, K. Merkley, C. Stimpson, and C. Ernst. MOAB: A mesh-oriented database. Technical Report SAND2004-1592, Sandia National Laboratories, Albuquerque, NM, 2004.

T. J. Tautges, P. F. Fischer, I. Grindeanu, R. Jain, A. Mahajan, A. V. Obabko, M. A. Smith, E. Merzari, and R. Ferencz. SHARP Assembly-Scale Multiphysics Demonstration Simulations. Technical Report ANL/MCS-NE-13-9, Argonne National Laboratory, March 2013. 